\title{
NON-OPERATIVE MANAGEMENT OF THE SIGMOID VOLVULUS - CASE PRESENTATION
}

\author{
Bogdan SOCEA ${ }^{1 凶}$, Alexandru C. SMARANDA ${ }^{1}$, Anca A. NICA ${ }^{1}$, Ovidiu G. BRATU ${ }^{2}$, \\ Camelia C. DIACONU ${ }^{3}$, Vlad D. BĂLEANU ${ }^{1}$, Cezar E. MOCULESCU ${ }^{1}$, Mihai DIMITRIU, \\ Alexandru C. CARÂP ${ }^{1}$, Simona BOBIC ${ }^{1}$, Vlad D. CONSTANTIN ${ }^{1}$
}

${ }^{1}$ Emergency Clinical Hospital „Sfântul Pantelimon“, General Surgery Clinic, „Carol Davila“ University of Medicine and Pharmacy, Bucharest, Romania

${ }^{2}$ Emergency Universitary Central Military Hospital, Department of Urology, „Carol Davila“ University of Medicine and Pharmacy, Academy of Romanian Scientists, Bucharest, Romania

${ }^{3}$ Internal Medicine, Cardiology, Emergency Clinical Hospital of Bucharest, „Carol Davila“ University of Medicine and Pharmacy, Bucharest, Romania

${ }^{4}$ Emergency Clinical Hospital „Sfântul Pantelimon“, Obstetrics and Gynecology Clinic, „Carol Davila“ University of Medicine and Pharmacy, Bucharest, Romania

Received 24 Sept 2018, Accepted 15 Nov 2018

https://doi.org/10.31688/ABMU.2018.53.4.24

\section{Abstract}

Sigmoid volvulus happens when the sigmoid wraps around itself and its mesentery. Sigmoid volvulus accounts for $2 \%$ to $50 \%$ of all colonic obstructions. This pathology generally affects adults, and it is more common in males. The etiology is multifactorial and controversial; the main symptoms are diffuse abdominal pain, distention and constipation, while the pregnant signs are abdominal distention and tenderness. Laboratory findings are not pathognomonic: abdominal X-ray radiographs show a dilated sigmoid colon and multiple intestinal air-fluid levels, abdominal CT and MRI demonstrate a whirled sigmoid mesentery. Flexible endoscopy reveals a spiral sphincter-like twist of the mucosa. The diagnosis of sigmoid volvulus is established by clinical, radiological, endoscopic, and sometimes operative findings. Although flexible endoscopic detorsion is advocated as the primary treatment

\section{Résumé}

Approche non opératoire du volvulus sigmoïde - présentation de cas

Le volvulus sigmoïde se produit lorsque le sigmoïde s'enroule autour de lui-même et de son mésentère. Le volvulus sigmoïde représente de $2 \%$ à $50 \%$ de toutes les obstructions coliques. Cette pathologie affecte généralement les adultes et est plus fréquente chez les hommes. L'étiologie est multifactorielle et controversée; les principaux symptômes sont douleur abdominale diffuse, distension et constipation, tandis que les signes de grossesse sont distension et sensibilité abdominales. Les résultats de laboratoire ne sont pas pathognomoniques: les radiographies abdominales montrent un côlon sigmoïde dilaté et de multiples niveaux de liquide intestinal, le scanner abdominal et l'IRM montrent un mésentère sigmoïde en tournoiement. 
choice, emergency surgery is required for patients who present with peritonitis, bowel gangrene, or perforation, or for patients whose non-operative treatment is unsuccessful. Although emergency surgery includes various non-definitive or definitive procedures, resection with primary anastomosis is the most commonly recommended procedure. After a successful non-operative detorsion, elective sigmoid resection and anastomosis is recommended. The overall mortality is $10 \%$ to $50 \%$, while the overall morbidity is $6 \%$ to $24 \%$.

Keywords: sigmoid volvulus, non-operative management of volvulus, elective sigmoid resection.

\section{INTRODUCTION}

In this article, we present the case of a 71-year-old female patient, who presented to our clinic with sigmoid volvulus associated with Parkinson's disease and senile dementia, which are frequently associated pathologies.

The volvulus of the sigmoid is the most common type of volvulation, representing $5-7 \%$ of all bowel obstructions $^{1,2}$.

There are multiple types of ways through which the sigmoid colon can volvulate:

- The most frequent type of volvulus is with a megadolichocolon, having a thick colonic wall, usually in patients with a high fiber diet and who present subacute symptoms.

- Megadolichosigmoid presenting a thin wall, with acute onset, representing a less frequent situation.

- A complex volvulus, in which a small bowel volvulus is volvulated around a sigmoid volvulus.

The early symptoms are represented by the absence of gas passing and lack of bowel movement, followed by abdominal distention which may be associated with asymmetry and with distention in the left iliac fossa. The great abdominal distention may create respiratory discomfort. At the onset of the symptoms, there is a discrepancy between the patient's lack of symptoms and the impressive abdominal distention. This pathology is usually present in elderly patients, known to suffer from chronic constipation or psychiatric afflictions. It is not well understood why the volvulus of the sigmoid happens, but some factors may be involved: a longer mesosigmoid, a high fiber diet,
L’endoscopie flexible révèle une torsion spiralée de la muqueuse en forme de sphincter. Le diagnostic du volvulus sigmoïde est établi par des résultats cliniques, radiologiques, endoscopiques et parfois opératoires. Bien que la détorsion endoscopique flexible soit préconisée comme traitement principal, une intervention chirurgicale d'urgence est nécessaire chez les patients présentant une péritonite, une gangrène intestinale ou une perforation, ou chez les patients dont le traitement non chirurgical est infructueux. Bien que la chirurgie d'urgence comporte diverses procédures non définitives ou définitives, la résection avec une anastomose primaire est la procédure la plus couramment recommandée. Après une détorsion non opératoire réussie, une résection sigmoïde et une anastomose sont recommandées. La mortalité globale est de $10 \%$ à $50 \%$, tandis que la morbidité globale est de $6 \%$ à $24 \%$.

Mots-clés: volvulus sigmoïde, approche non opératoire du volvulus, résection sigmoïde.

the narrow insertion of the pelvic colon and chronic constipation.

\section{Case presentation}

We present the case of a 71 year-old female patient, who presented to the emergency room with important abdominal distention, diffuse abdominal pain and the absence of bowel movement for approximately 3 days. The patient was admitted to our surgical ward for further investigation. The elderly patient was known with history of Parkinson's syndrome, atrial fibrillation, class II arterial hypertension, senile dementia, megacolon, type II diabetes and a history of volvulation of the sigmoid, which was resolved spontaneously on the past admission.

A clinical examination showed distention of the abdomen, with diffuse pain and hypersonority at percussion. The rectal examination was uneventful.

The blood tests show a small elevation of the leukocytes $(11.400 / \mathrm{uL})$ and anemia $(9.10 \mathrm{~g} / \mathrm{dL})$, with no changes of the other laboratory values.

The abdominal X-ray exam shows distention of the left colon and massive aerocoly (Figures 1 and 2).

A few hours after a rectal tube was introduced, the general state of the patient improved and there was a decompression of the abdomen through the elimination of gas and feces through the tube. The tube was removed and the patient maintained her good general state over the day. The second day after admission, the patient's abdomen started to be meteorized and the lack of bowel movement was again present. The rectal exam was again uneventful. We 


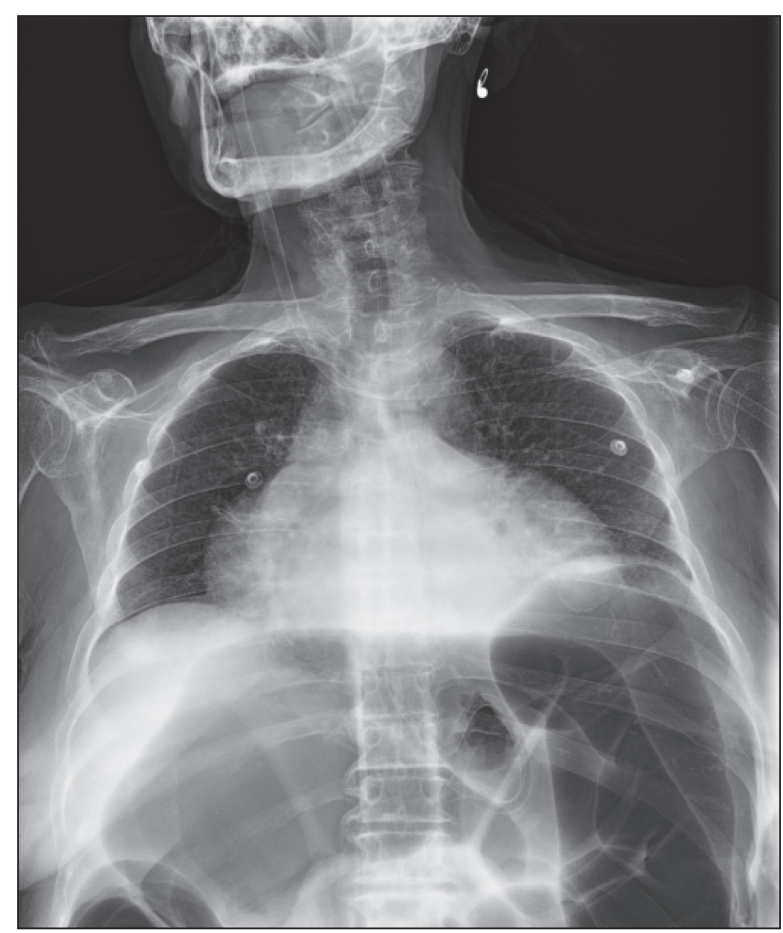

Figure 1. X-Ray: distention of the left colon

suggested a surgical intervention, but the patient refused. We reintroduced a rectal tube and the abdomen was again decompressed. The tube was maintained for two days and removed after. The next two days after the removal of the tube, the patient maintained the bowel movements for feces and gas. The patient was discharged in the $6^{\text {th }}$ day, with an uneventful outcome. She was advised that the surgical intervention is necessary for preventing the relapse of colonic volvulus, but refused the intervention.

\section{Discussion}

Sigmoid volvulus represents one of the causes of an acute surgical abdomen. The degree of torsion may differ between $180^{\circ}$ (in $35 \%$ of cases) and $540^{\circ}$ (representing approximately $10 \%$ of the cases). A $360^{\circ}$ torsion is present in $50 \%$ of patients with sigmoid volvulus ${ }^{3}$. The colonic segment may or may not present necrosis. If the vascular integrity of the sigmoid is not affected, a sigmoidoscopy may be performed to devolvulate the colon. Surgical intervention is necessary to prevent the further relapse of the symptomatology and the revolvulation of the colon segment which is quite frequent $t^{4-6}$.

The actual incidence of sigmoid volvulus is unknown. It usually appears in people aged over 50 with neurological or psychiatric problems. Chronic constipation is the most common symptom present

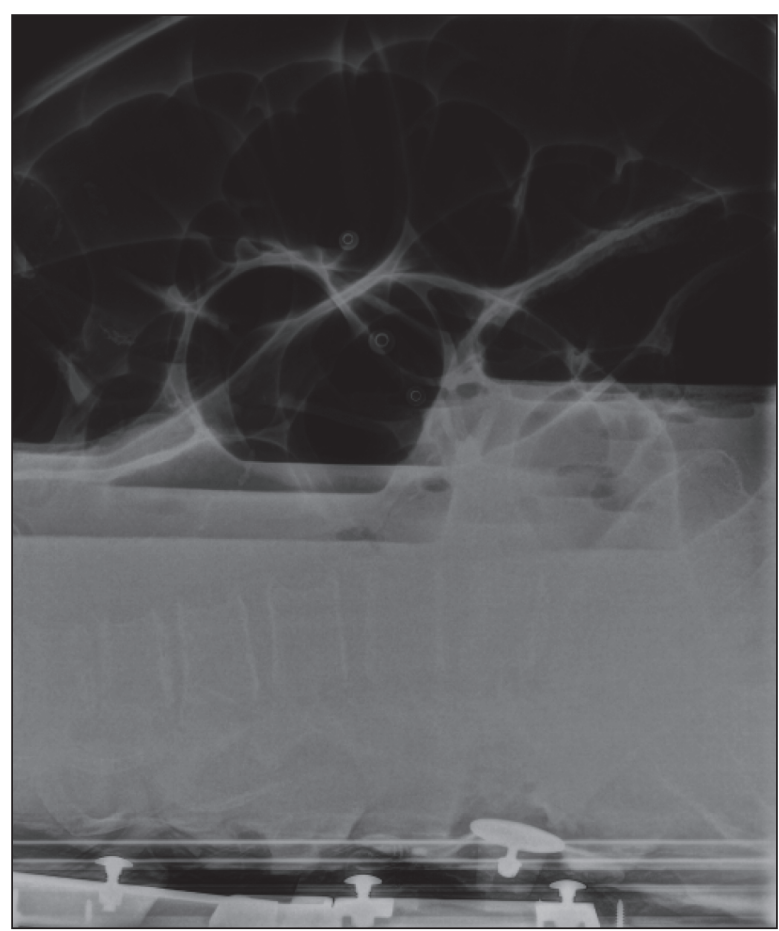

Figure 2. Massive aerocoly on the abdominal simple radiography

in these patients. Sigmoid volvulus is more common in men (64\%) and in African Americans (67\%)7. The lower incidence in women seems to be due to the large pelvis? The sigmoid volvulus is responsible for $5-7 \%$ of the obstructions of the intestinal tract, with an increased mortality rate (20-25\%), which depends on the interval between symptom onset and initiation of the treatment ${ }^{8}$.

The most common cause of sigmoid volvulus is the presence of a long sigmoid colon (dolichosigmoid), encountered in patients with Parkinson's disease, which is also in our case, multiple sclerosis, neurological and / or psychiatric disorders. Inhibition of colon motility by using psychotropic medication, as well as primary motility disorders, favor the elongation of the sigmoid and predisposes to its twisting around the mesentery, opposite from increased motility that favors intussusception.11. Similarly, patients with narrow mesosigmoid are predisposed to sigmoid volvulus by affecting colon mobility. Hirschsprung's disease interests the myenteric plexus of the colon and favors the growth in size of its lumen and predisposes to volvulation. Chronic constipation, most commonly present in sedentary people, is another cause of sigmoid volvulus. Another important etiological factor is the repeated use of laxatives and enemas ${ }^{12-15}$.

Other methods of treatment for sigmoid volvulus are: mesosigmoidoplasty and percutaneous endoscopic sigmoidopexy ${ }^{16}$. Martinez et al show that the 
endoscopic reduction of sigmoid volvulus is effective, but the rate of recurrence is big ${ }^{11}$. Although all these authors reported a small series of alternative treatments, resection of the sigmoid segment remains the most recommended treatment $t^{4,1721}$.

\section{Conclusions}

The patient's clinical examination and simple abdominal radiography allow the diagnosis of sigmoid volvulus. Early diagnosis is particularly important for the prognosis and further development of the case. In the absence of the possibilities of endoscopic devolvulation or insertion of a rectal tube, early intervention is necessary. In our case, we also confronted with a refusal of surgery. Given the possible changes in the colon vasculature, Hartmann's procedure is preferred, followed by the restoration of digestive tract continuity after 6 weeks.

\section{Compliance with Ethics Requirements:}

"The authors declare no conflict of interest regarding this article"

„The authors declare that all the procedures and experiments of this study respect the ethical standards in the Helsinki Declaration of 1975, as revised in 2008(5), as well as the national law. Informed consent was obtained from the patient included in the study"

"No funding for this study"

\section{References}

1. Drelichman ER, Nelson H. Colonic volvulus. In: Cameron JL, editor. Current surgical therapy 2004, 8th ed. St. Louis: C.V. Mosby.

2. Turan M, Sen M, Karadayi K, et al. Our sigmoid volvulus experience and benefits of colonoscope in detortion process. Rev Esp Enferm Dig 2004; 96(1):32-35.

3. Echenique Elizondo M, Amondarain Arratibel JA. Colonic volvulus. Rev Esp Enferm Dig 2002;94: 201-210.

4. Renzulli P, Maurer CA, Netzer P, Buchler MW. Preoperative colonoscopic derotation is beneficial in acute colonic volvulus. Dig Surg 2002; 19:223-229.
5. Sturzaker HG, Lawrie RS, Joiner CL. Recurrent sigmoid volvulus in young people: a missed diagnosis. Br Med J 1975; 4:338-339.

6. Mokoena TR, Madiba TE. Sigmoid volvulus among Africans in Durban. Trop Geogr Med 1995; 47:216-217.

7. Ballantyne GH. Review of sigmoid volvulus: history and results of treatment. Dis Colon Rectum 1982; 25:494-501.

8. Grossmann EM, Longo WE, Stratton MD, Virgo KS, Johnson FE. Sigmoid volvulus in Department of Veterans Affairs Medical Centers. Dis Colon Rectum 2000; 43(3):414-418.

9. Bumbu A, Pasca B, Tit DM, Bungau S, Bumbu G. The effects of soy isoflavones and hormonal replacing therapy on the incidence and evolution of postmenopausal female urinary incontinence. Farmacia 2016; 64(3):419-422.

10. Bungau S, Bungau C, Tit DM, Pallag A. The influence of specialized academic studies on self-medication. Rev Rom Bioet 2015; 13(1):153-158.

11. Socea B, Nica AA, Bratu OG, et al. Incidental finding of a sigmoid intussusception associated with rectal prolapse - A case report. Arch Balk Med Union 2018; 53(1):143-146.

12. Diaconescu D, Pantea Stoian A, Socea LI, et al. Hepatorenal syndrome: a review. Arch Balk Med Union 2018; 53(2): 239-245.

13. Diaconu CC, Manea M, Iancu MA, et al. Hyponatremia in patients with heart failure: a prognostic marker. Rev Chim (Bucharest) 2018; 69(5):1071-1074.

14. Pallag A, Rosca E, Tit DM, Mutiu G, Bungau SG, Pop OL. Monitoring the effects of treatment in colon cancer cells using immunohistochemical and histoenzymatic techniques. Rom J Morphol Embriol 2015;56(3):1103-1109.

15. Stanimir M, Chiutu LC, Wese S, Milulescu A, Nemes RN, Bratu O. Mullerianosis of the urinary bladder: a rare case report and review of the literature. Rom J Morphol Embriol 2016; 57(Suppl 2): 849-852.

16. Bach O, Rudloff U, Post S. Modification of mesosigmoidoplasty for nongangrenous sigmoid volvulus. World J Surg 2003; 27:1329-1332.

17. Martínez Ares D, Yáñez López J, Souto Ruzo J, et al. Indication and results of endoscopic management of sigmoid volvulus. Rev Esp Enferm Dig 2003; 95(8):544-548.

18. Atamanalp SS. Sigmoid volvulus. Eurasian J Med 2010; 42(3):142-147.

19. Constantin V, Carap A, Bobic S, et al. Accurate diagnosis of sigmoid colon endometriosis by immunohistochemistry and transmission electron microscopy - A case report. Chirurgia (Bucur) 2015; 110(5):482-5.

20. Diaconu CC, Dragoi CM, Bratu OG, et al. New approaches and perspectives for the pharmacological treatment of arterial hypertension. Farmacia 2018; 66(3):408-415.

21. Diaconu CC, Stănescu AMA, Pantea Stoian A, et al. Hyperkalemia and cardiovascular diseases: new molecules for the treatment. Rev Chim (Bucharest) 2018; 69(6):1367-1370. 